\title{
Emergency Procedure Applied to Tackle the Lack of Sphericity after Cutting the Bone Bed for Cementless Hip Arthroplasty - The Acetabular Screw-Cup System Developed by Aesculap
}

Jan Poszepczyński ${ }^{*}$, Ewa Pawłowicz ${ }^{2}$, Krzysztof Andrzejewski ${ }^{1}$, Radosław Grabowski ${ }^{1}$, Jedrzej Lesman ${ }^{1}$, Tomasz Janczyk ${ }^{1}$ and Marcin Domżalski ${ }^{1}$

${ }^{1}$ Department of Orthopedics and Trauma, Medical University of Lodz, Veteran's Memorial Hospital, Lodz, Poland

${ }^{2}$ Department of Nephrology, Hypertension and Kidney Transplantation, Medical University of Lodz, Poland

Correspondence should be addressed to Jan Poszepczyński, janek24061982@tlen.pl

Received: February 06, 2021; Accepted: March 05, 2021; Published: March 12, 2021

\section{$\underline{\text { ABSTRACT }}$}

\section{BACKGROUND}

The study aimed to analyze the complications following cementless arthroplasty surgery where original sphericity was not obtained and screw-cap system was required.

\section{METHOD}

The study inclusion criteria were met by 39 patients aged 47 - 90 and the mean follow-up period was 54 months. Patients were operated in a lateral position, through the posterolateral or minimal posterior approach.To assess postoperative functionality, Harris Hip Score and Hoos questionnaire were applied.

\section{RESULTS}

According to the Harris Hip Score, $64.3 \%$ of the scores were very good and good and the mean score was 96 according to the Hoos questionnaire. The incision type, BMI and the type of cutaneous suture had no impact on the functional outcome, incidence of complications and a pain rate in the groin. Scar esthetics received highest scores from the patients operated through the minimal posterior approach and treated with a running intra-cutaneous suture. Yet a lateral position during the surgery made any intraoperative assessment of the limb length considerably more difficult. Consequently, $30 \%$ of the operated patients reported different limb lengths, which significantly $(\mathrm{p}=0.036)$ lowered a functional outcome measured according to the HOOS and Harris Hip Score. The functional outcomes demonstrate a considerably negative correlation with age but not with gender although men are more vulnerable to the postoperative complications $(\mathrm{p}=0.18)$.

Citation: Jan Poszepczyński, Emergency procedure applied to tackle the lack of sphericity after cutting the bone bed for cementless hip arthroplasty - The acetabular screw-cup system developed by aesculap. J Clin Cases Rep 4(S9): 21-27. 
http://www.tridhascholars.org | June-2021

\section{CONCLUSION}

Despite a relatively large number of complications following the surgery using a screw-cap system, $75 \%$ of the patients declared they would not mind another surgery using such system.

\section{KEYWORDS}

Cementless hip arthroplasty; Sphericity; Screw cup system; Limb length

\section{INTRODUCTION}

An effective and long-standing mode of treatment of the advanced degenerative disease of the hip is total cementless hip arthroplasty with press-fit cup implantation [1-5]. The screw in cup is an implant that has been tested and proven in relation to prostheses consisting of a acetabular component of a ceramic, ceramic head and a metal stem as various modifications of the Mittelmeier prosthesis have been used successfully in the past [6-9].

We found no literature data on the assessment of the joint functionality after implantation of screw cup system developed by Aesculap after an ideal sphericity had not been obtained in the course of the preparation of cicatrix for the implantation of the cementless hip arthroplasty. The literature on the cementless arthroplasty provides no data about neither functional differences nor survivability of the implant, depending on the applied articulation (metal - polyethylene $v s$. ceramic - ceramic) [10].

\section{Aim}

The paper is aimed to assess the outcomes of the hip degenerative disease treatment using screw cup system in the patients where implant was chosen intraoperatively due to the failure to provide sphericity indispensable for the cup implantation using the press-fit technique.

\section{MATERIALS AND METHOD}

We performed a retrospective analysis of the X-ray evidence and the findings of a survey made by post, where 39 patients were treated in our department in the years from 2010 - 2018. During that time we performed 432 cementless hip arthroplasty operations in general.
The operated patients were aged $47-90$ (mean age $=68.9$ \pm 11.9). The follow-up time ranged between 28 months and 132 months (mean time $=54$ ). In the period between surgery and study, 3 people died. The study group characteristics is given in (Table 1). The X-ray diagnostics was always performed prior to the surgery. Patients were originally planned for cementless arthroplasty using the press-fit cup technique. An intraoperative decision about the use of screw-cup system resulted from the lack of ideal sphericity needed to implement the press-fit arthroplasty (negative trial cup test).

\section{Surgical Techniques}

Patients were placed in the lateral position. Depending on the operator's decision, patients were operated using either the posterolateral or the minimal posterior approach (MPA in short).

A classical posterolateral approach involves a $10 \mathrm{~cm}-15$ $\mathrm{cm}$ long, curved incision made 1 inch posterior to the posterior edge of the greater trochanter (GT). The incision begins $7 \mathrm{~cm}$ above, is curved posterior to the GT and continued down the femoral shaft. Then fascia lata is incised to uncover vastus lateralis and the fascial incision is distally lengthened in line with the skin incision. Gluteus maximus fibers are split and vessels cauterized to avoid excessive blood loss. The next step includes a deep dissection rotating the hip internally to place the short external rotators on stretch, while the suture stay is placed inpiriformis and obturator internus tendon (short external rotators). Finally, piriformis and obturator internus are detached close to the femoral insertion and reflected 
backwards to protect sciatic nerveand capsule incised longitudinally.

A minimal posterior approach involves a $8 \mathrm{~cm}-10 \mathrm{~cm}$ long, curved incision posterior to the GT and continued slightly down the gluteus shaft. After that an incision is made in fascia lata to uncover vastus lateralis proximally a fascial incision in line with the skin incision, glutus maximus fibers are split and vessels cauterized in the proximal incision to avoid excessive blood loss. The next step includes a deep dissection rotating the hip internally to place the short external rotators on stretch, while the suture stay is placed inpiriformis and obturator internus tendon (short external rotators). Then piriformis and obturator internus are detached close to the femoral insertion and reflect backwards to protect sciatic nerve. This is followed by the T-shaped incision made in capsule. The hip joint is dislocated back and the femoral neck cut $1 \mathrm{~cm}$ above the GT. Next, we prepare the spherical surface without cartilage for mounting the cup using a low-speed spherical reamers. The final selection of press-fit cup is determined only after a trial cup had been seated firmly. A stable fit of this trial cup is achieved when the pelvis can be moved by gently moving the trial cup by about 10 degree. An intraoperative decision about the use of screw-cup system resulted from the lack of ideal sphericity needed to implement the press-fit arthroplasty.

We made use of the metal head and polyethylene cup articulation, which is more advantageous in financial terms.

Next, the functional outcomes were assessed using the Harris Hip Score and Hoos measure tools when patients reported to the orthopedic outpatient clinic or based on the survey sent to the respondents by post. All patients after THR had doppler assessment due to thrombosis suspicion. None of them had positive result.

\section{Method}

During the operation, we always used the original instruments and implants for the implantation of the screw cup system (BBraun/Aesculap, Germany).

The results are presented as a mean \pm standard deviation (SD) or median and interquartile range for normally and non-normally distributed variables, respectively. The distribution of continuous values was assessed with the Shapiro-Wilk test. Depending on the variable's distribution, t-test or Mann-Whitney U test were used for comparisons between independent groups. One-way ANOVA and Kruskal-Wallis test were used for comparisons of normally and non-normally distributed variables of three independent groups. Correlations were performed with Person or Spearman method. For comparisons of categorical variables, Fisher test was used. Multiple linear regression analysis was performed.

An alpha level of $\mathrm{p}<0.05$ was required for significance. Statistical analysis was performed with Statistica versues 13.0 PL software and graphs were plotted with GraphPad Prism application vs. 6.01 for Windows.

\section{RESULTS}

We excluded 3 patients ( 1 woman and 2 men) from the functional study due to their death after being discharged from hospital and 9 patients who had the hip re-operated (5 women and 4 men) (Table 1 ).

\begin{tabular}{|c|c|}
\hline Characteristics & N (\%) \\
\hline Gender & \\
\hline Female & $22(56.4 \%)$ \\
\hline Male & $17(43.6 \%)$ \\
\hline Age (mean \pm SD) & $68.9 \pm 11.9$ \\
\hline$>$ 75 Years Old & $14(35.9 \%)$ \\
\hline$<75$ Years Old & $25(64.1 \%)$ \\
\hline BMI (Median [IQR]) & $28[5.6]$ \\
\hline Normal Weight & $12(30.8 \%)$ \\
\hline Overweight & $17(43.6 \%)$ \\
\hline Obesity & $10(25.6 \%)$ \\
\hline
\end{tabular}

Table 1: Study group $(\mathrm{N}=39)$ characteristics. 
Hip function was assessed using the Harris Hip Score and $64.3 \%$ of results were very good and good.
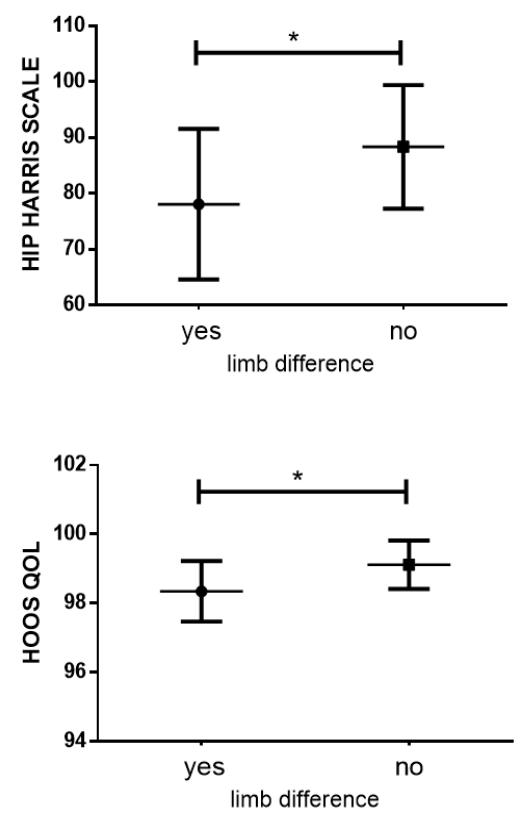

Patients with a subjective sense of the limb difference had statistically significantly lower functional scores (Figure 1).
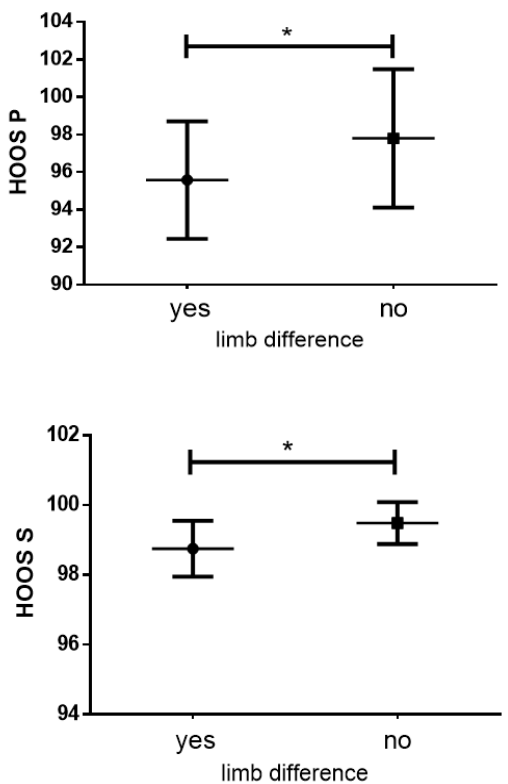

Figure 1: Scores according to Harris Hip Score and HOOS in patients with and without subjective sense of limb difference $(* \mathrm{p}<0.05)$.

A correlation between age and functional outcome was negative (Figure 2).
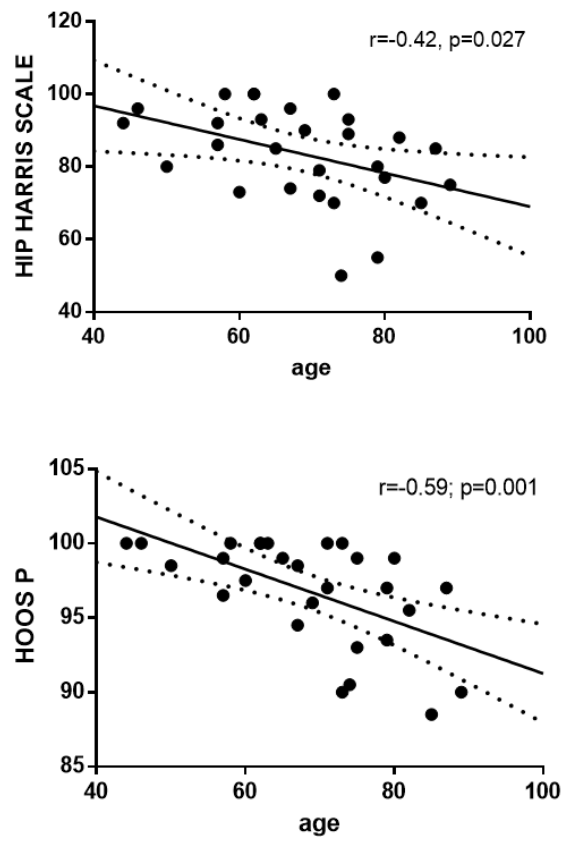

Patients operated using intra-cutaneous suture found their scar aesthetics considerably better than those where interrupted suture was applied $(\mathrm{p}=0.05)$.
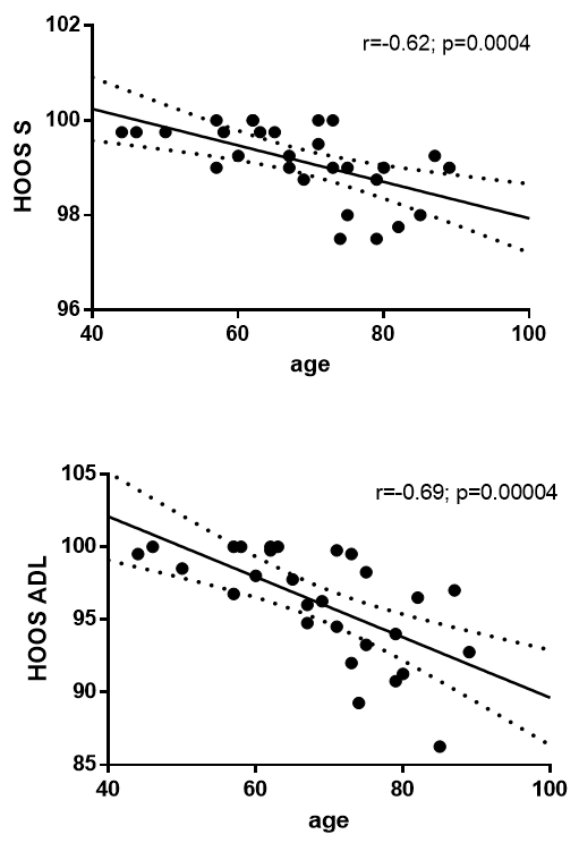

Figure 2: Correlation between age and functional outcome according to Harris Hip Score and HOOS. 
Due to a small number of patients with complications, an impact of specific variables on the incidence of specific complications is difficult to assess (Table 2).

\begin{tabular}{|c|c|}
\hline Complication & $\mathbf{N}(\%)$ \\
\hline Loosening & \\
\hline Aseptic & $4(10.3 \%)$ \\
\hline Septic & $3(7.7 \%)$ \\
\hline Dislocation & $4(10.3 \%)$ \\
\hline Periprosthetic Fracture & $1(2.6 \%)$ \\
\hline
\end{tabular}

Table 2: Postoperative complications.

The data suggests that BMI, age, type of incision (classical posterolateral vs. minimal posterior approach), type of suture (intra - cutaneous vs. interrupted) had no impact on the incidence of complications.

There is no statistically significant relationship between gender and incidence of complications $(p=0.18)$ although it is slightly higher in men - postoperative complications were observed in $52.9 \%$ of men and only $27.3 \%$ of women.

The type of incision (posterolateral vs. minimal posterior approach $)(\mathrm{p}=0.63)$ and BMI $(\mathrm{p}=0.91)$ has no impact on the incidence of subjective sense of pain in the groin.

\begin{tabular}{|c|c|c|c|c|c|c|c|c|c|c|c|c|c|c|c|}
\hline \multirow{2}{*}{$\begin{array}{l}\text { Dependent } \\
\text { var. } \\
\text { Parameter }\end{array}$} & \multicolumn{3}{|c|}{ HARRIS, $\mathbf{R}^{2}=0.34$} & \multicolumn{3}{|c|}{ HOOS QOL, $\mathbf{R}^{2}=0.39$} & \multicolumn{3}{|c|}{ HOOS S, $R^{2}=0.59$} & \multicolumn{3}{|c|}{ HOOS P, $R^{2}=0.44$} & \multicolumn{3}{|c|}{ HOOS ADL, $\mathbf{R}^{2}=0.47$} \\
\hline & $\beta$ & $\mathrm{p}$ & $95 \% \mathrm{CI}$ & $\beta$ & $\mathrm{p}$ & $95 \% \mathrm{CI}$ & $\beta$ & $\mathrm{p}$ & $95^{\circ}$ & $\beta$ & $\mathrm{p}$ & 950 & $\beta$ & $\mathrm{p}$ & $\mathrm{CI}$ \\
\hline Age (years) & -0.46 & 0.02 & $-0.84,-0.07$ & -0.26 & 0.16 & $-0.62,0.11$ & -0.49 & 0.002 & $-0.79,-0.19$ & -0.59 & 0.002 & $-0.95,-0.24$ & -0.67 & 0.0004 & $-1.02,-0.34$ \\
\hline BMII & -0.12 & 0.53 & 6 & 0.26 & 0.15 & -0.0 & 0.23 & 0.122 & .53 & -0.01 & 0.942 & -0.3 & -0.05 & 0.74 & -0.3 \\
\hline Length of limbs & -0.36 & 0.04 & $-0.72,-0.01$ & -0.46 & 0.01 & $-0.80,0.13$ & -0.47 & 0.002 & $-0.75,-0.19$ & -0.28 & 0.083 & -0.6 & -0.17 & 0.25 & $-0.49,0.13$ \\
\hline Incision & 0.13 & 0.46 & $-0.23,0.48$ & 0.18 & 0.29 & $-0.16,0.52$ & 0.16 & 0.237 & $-0.11,0.44$ & 0.16 & 0.324 & $-0.17,0.49$ & -0.12 & 0.42 & $-.019,0.44$ \\
\hline
\end{tabular}

Table 3: Multiple linear regression for Harris and HOOS QOL, S, P, and ADL scales. We found the aseptic hip cup loosening in 4 patients: 2 people reported hip injury due to the fall on the affected aspect, which resulted in pain, suggesting that loosening was caused by a mechanical factor.

\section{DISCUSSION}

An effective mode of treatment of the degenerative disease of the hip is arthroplasty operation using the cementless press-fit system $[1-5,10,11]$. There is no convincing literature recommendations how the cup should be fixed when ideal sphericity was not obtained after cutting a bone bed for the acetabulum using the press-fit technique. In such cases, the cemented arthroplasty advocates recommend a hybrid surgery that produces a better functional effect than the screw-cup system (cemented acetabulum, stem fixed with no cement) $[12,13]$. Similarly to the findings of other authors, our study confirms that BMI, gender, type of incision and cutaneous suture have no impact on the functional outcome and incidence of complications following the hip arthroplasty operation [14]. Moreover, we demonstrate that there is a high negative correlation between functional outcomes and age, which is not reflected in the literature [15]. Our study confirms that hip arthroplasty is an excellent mode of treatment of the degenerative disease, ensuring return to typical physical activity or sometimes even sport [16]. This is similar to the findings of other authors. Yet, in a number of cases, such a procedure requires great skills and wide experience [17]. As we applied low molecular weight heparin in prophylactic dose, we found no incidence of the deep vein thrombosis, which is a common complication discussed extensively in the literature [18]. We also found no studies on the dislocation of arthroplasty insert, another complication diagnosed after the cementless arthroplasty surgery.

\section{CONCLUSION}

Screw cup system produces only a good and very good functional outcome in $64.3 \%$ of patients and may be used as a rescue procedure when ideal sphericity cannot be obtained after cutting the hip acetabulum.

Patients who had a subjective sense of unequal length of their limbs obtained functional outcomes significantly 
lower in statistical terms than those with the limbs of the same length. The functional outcomes demonstrate a strong negative correlation with age.

The data that we obtained indicates that BMI, age, type of incision (classical posterolateral vs. minimal posterior approach), type of suture (intra-cutaneous vs. interrupted) neither contributed to any complications nor had any impact on the functional outcome.

Relationship between gender and complications is insignificant in statistical terms but men demonstrate a slightly higher incidence of complications $(\mathrm{p}=0.18)$.

A type of operative incision has no impact on the incidence of subjective sense of pain in the groin and subjective assessment of the scar esthetics. Application of the intra-cutaneous suture after the surgery performed using the low-invasive minimal posterior approach has a significant impact on the assessment of the postoperative scar esthetics. Given a small number of patients with specific complications, an impact of specific variables on the incidence of these complications is difficult to assess. Yet in the majority of cases, aseptic loosening of arthroplasty was proceeded by the injuries of the affected hip.

\section{DATA AVAILABILITY}

The reader may obtain all data supporting the results and conclusions of the study upon written request to the corresponding author.

\section{CONFLICT OF INTEREST}

There are no conflict of interests for any author.

\section{FUNDING}

This research was funded from the budgetary resources of the two research centers (Department of Orthopedics and Traumatology, Military Medical Academy Memorial Teaching Hospital in Lodz, Poland and Department of Nephrology, Hypertension and Kidney Transplantation, Medical University of Lodz, Poland) under the own activities of researchers.

\section{ETHICS APPROVAL}

Approval from the ethical board at our local University was obtained (RNN/250/19/KE ) for the study design and to acquire data from medical records for this study and informed consent was obtained from all participants

\section{REFERENCES}

1. Drobniewski M, Borowski A, Synder M, et al. (2014) Cementless total hip arthroplasty with bicontact stem - go odd results at long term of follow up. Ortopedia, Traumatologia, Rehabilitacja 16(1): 1-9.

2. Ateschrang A, Weise K, Weller S, et al. (2014) Long-term results using the straight tapered femoral cementless hip stem in total hip arthroplasty: A minimum of twenty year follow up. Journal of Arthroplasty 29(8): 1559-1565.

3. Drobniewski M, Synder M, Krajewski K, et al. (2012) Comparison of early results of hip arthroplasty with the use of bicontact and antega stem in the treatment of severe coxarthrosis. Polish Orthopaedics and Traumatology 77: 91-94.

4. Špička J, Radová L, Gallo J (2012) Cementless plasmacup bicontact total hip arthroplasty. Results of a minimum of tenyear follow-up. Acta chirurgiae orthopaedicae et traumatologiae Cechoslovaca 79(4): 317-323.

5. Lerch M, Kurtz A, Windhagen H, et al. (2012) The cementless bicontact stem in a prospective dual-energy x-ray absorptiometry study. International Orthopaedics 36(11): 2211-2217.

6. Grzegorzewski A, Zwierzchowski H, Synder M (1998) Radiological assessment of the hip after Mittelmeier and ParhoferMönch stem implantation. Chirurgia narzadów ruchu i ortopedia polska 63(6): 535-539. 
http://www.tridhascholars.org | June-2021

7. Grabowski MT, Mittelmeier H (1985) 10 years of experience with ceramic hip prosthesis. Materials of the 25th Jubilee Scientific Congress of the Polish Orthopedic and Traumatological Society, Łódź, 267-270.

8. Mittelmeier H, Grabowski M (1994) 10 years experience with metal-granular coating of cementless auto-phor-hipprosthesis and titanium polyethylene screw cup cst. Chirurgia narzadów ruchu i ortopedia polska 59: 223-227.

9. Mittelmeier H (1986) Grundlage und algemeine Erfahrungen mit dem Keramik-Prothesen-System Autophor/Xenophor. 10 jahre Erfahrungen mit Keramik-Huftendoprothesen. Mittelmeierund Heisel, Medizinische Literarische Verlaggeselschaft mbH - Uelzen, 9-32.

10. Ochs U, Ilchmann T, Ochs BG, et al. (2007) EBRA migration patterns of the plasmacup with ceramic or polyethylene inserts: A randomised study. Zeitschrift fur Orthopadie und Unfallchirurgie 145 Suppl 1: S20-S24.

11. Swamy G, Pace A, Quah C, et al. (2012) The bicontact cementless primary total hip arthroplasty: Long-term results. International Orthopaedics 36(5): 915-920.

12. Kubinec V (2018) Influence of the type of hip-component fixation and age of patients on mid-term revision rate of total hip replacement. Acta chirurgiae orthopaedicae et traumatologiae Cechoslovaca 85(1): 46-53.

13. Ahmad A, Mirza Y, Evans AR, et al. (2018) A comparative study between uncemented and hybrid total hip arthroplasty in octogenarians. Journal of Arthroplasty 33(12): 3719-3723.

14. Jain S, Magra M, Dube B, et al. (2018) Reverse hybrid total hip arthroplasty. Bone Joint Journal 100-B(8): 1010-1017.

15. Badhe NP, Quinnell RC, Howard PW (2002) The uncemented bicontact total hip arthroplasty in octogenarians - Medium term results. European Journal of Orthopaedic Surgery \& Traumatology 12(4): 192-197.

16. Bradley MB, Moul JS, Doyle JF, et al. (2017) Return to sporting activity after total hip arthroplasty - A survey of members of the british hip society. Journal of Arthroplasty 32(3): 898-902.

17. Staats K, Kubista B, Windhager R (2019) Challenges in primary total hip arthroplasty. Zeitschrift fur Orthopadie und Unfallchirurgie 157(4): 445-460.

18. Dohmae Y (2003) Plasmacup special design. Aspects of the dysplastic acetabulum. International Orthopaedics 27 Suppl 1: S20-S23. 